CHAPTER 13

\title{
Why living heritage sites cannot be embraced within the current approaches to conservation?
}

\author{
Discontinuity vs. continuity (criteria)
}

The current theoretical framework and practice of heritage conservation in the context of a material-based and a values-based approach, despite its developments over time particularly on the basis of the Nara Document on Authenticity (see Part 1), is still based on discontinuity created between the monuments of the past and the people of the present and heavily focuses on the preservation of the authenticity of the fabric (see Part 1), and therefore seems unable to embrace the concept of a living heritage site. This discontinuity created by heritage conservation between the past and the present contradicts the continuity of a living heritage site, as expressed in the four criteria. Specifically:

a) The continuity of the heritage site's original function - the purpose for which the site was originally intended.

The current theoretical framework and practice of heritage conservation is mostly based on sites whose continuity of function has been broken.

b) The continuity of community's connection with the site.

In the context of discontinuity, conservation professionals, following a values-based approach, tend to see the core community of a living heritage site simply as a stakeholder group to be identified, taken into consideration and managed, and see the core community's connection with a site simply as a (group's) value to be classified and assessed. The concepts of value and stakeholder group, as classified in strict categories and rigorously assessed by conservation professionals, seem to run counter to the unified organic character of a living heritage site as the outcome of the inseparable connection between the core community and the site. The concept of the subjectivity and equity of values and of stakeholder groups (due to the lack of sufficient criteria and ways to set priorities and choose between them) is not applicable in the case of a living heritage site: in a living heritage site, the core community, because of its special association with the site, is clearly differentiated from the broader community. The concept of the increased power of one leading managing authority, mostly conservation professionals, over all the stakeholder groups seems to run counter to the primary importance and role of the core community in the operation and management of a living heritage site. Therefore, it could be argued that conservation professionals attempt to deprive, in a way, the core community of its special association with a site; they, 
instead, tend to establish and justify their own association with a site and their right to keep all stakeholder groups, including the core community, under their control. In this respect, conservation professionals see the concept of a living heritage site within their own association with a site (rather than within the core community's association with the site).

c) The continuity of the care of heritage sites by the community as expressed through community's management (and ownership) mechanisms and maintenance practices.

The current theoretical framework and practice of heritage conservation, in the context of a material-based and a values-based approach, are based on the notion that authenticity of sites is non-renewable and heavily focuses on the material and on elements of materiality, and on the principle that the power in the designing and implementation of the conservation process is in the hands of the conservation professionals. In this context, heritage conservation can embrace traditional mechanisms and practices only to the (limited) extent that these mechanisms and practices prove to have positive results in the preservation of the fabric of a site, and mostly in connection with modern scientific-based systems and practices and under the control of conservation professionals.

The World Heritage concept in particular can take on board only those traditional mechanisms and practices that prove to have positive results in the preservation of the fabric of the sites, in terms of authenticity and integrity: '... which should specify how the outstanding universal value of a property should be preserved' (UNESCO 2005). This emphasis on the preservation of the fabric of the sites implies that many practices would be rather unacceptable to the World Heritage concept. From the variety of practices discussed earlier, only examples of partial replacement of existing material with same material (which may be considered the simplest of the approaches in terms of materiality) can be embraced in the World Heritage context. In this line, some of the sites of this category have been inscribed on the World Heritage List, such as Meteora, the Kasubi tombs in Uganda, the Great Mosques of Timbuktu in Mali, the Hindu Temple at Tanjore in India, and the Buddhist Temple of the Tooth Relic as part of the city of Kandy in Sri Lanka. However, practices that do not consider the significance of the age of a structure (such as repainting of rock images) or that make the defining of the age of a structure very difficult in the first place (such as total physical renewal practices) are unlikely to be embraced within the World Heritage concept. Similarly, practices that do not consider the importance of the type of the original material are unlikely to be taken on board either (examples of such practices: those that define the material on the basis of the function of a structure, as in Hinduism, or those that require renewal of the material by a different material that would serve the function of the structure more effectively, as the partial replacement/renewal of existing material with same or different material). Additionally, practices that do not even consider the significance of an object as a whole (as with the practices of immersion or replacement of objects) are unacceptable to the World Heritage concept. Examples: The repainting of rock images in Australia (a case of total physical renewal) has often faced such accusations as that of 'desecration [of] some of the most significant relics of traditional Aboriginal culture in Australia... [and] irreparable damage [of] part of the cultural heritage of all mankind' (quoted in Bowdler 1988, 520; see also Ward 1992, 32-35). Repainting can be acceptable to the heritage authorities rather not in sites on the World Heritage List, and still in specific cases such as the Gibb River project and under very strict regulations (such as: not upon existing layers of significant cultural value or in a way that would not destroy the existing paintings, and only after the existing layers have been fully recorded) and still under severe conflicts (Mulvaney and Kamminga 1999, 361; Ward 1992, 32-35; pers. comm. Peter Sutton). In a similar context, in the site of Domboshava, part of Matobo Hills, in Zimbabwe (inscribed on the World Heritage List in 2003), repainting as part of rain-making rituals was banned and the local communities conducting the ritual were removed from the site by the heritage authorities in the 1980s. This ban later led to a serious conflict between the two sides and an act of severe damage to the rock paintings 
caused by the local communities. The result was that rain-making rituals have been accepted by the heritage authorities of the site, but have been relocated to another part of the site which does not interfere with the rock paintings (Pwiti and Mvenge 1996, 818-21; Taruvinga and Ndoro 2003, 5-9). Rain-making rituals were also banned from the site of Siloswane, also part of Madobo Hills, in Zimbabwe (Taruvinga and Ndoro 2003, 4; Ndoro 2004, 82). In another example, with regard to 'Shikinen Zotai' (an example of total physical renewal), Ise Shrine, which is the only shrine which continues the ritual in its pure form/in the entire precinct of the site, has not been designated as a national heritage let alone a World Heritage Site, because the ritual is seen as going beyond the assessments and classification of value and authenticity based on tangible form (Inaba 2005, 54). Only shrines in which the original ritual has not survived or has survived in a faded form have been designated as national heritage monuments, as is the case of 'Onbashira Matsuri' of Suwa Shrine (Inaba 2005, 52-53). The case of Kasubi tombs in Uganda could be seen in a similar context: The heritage authorities of the site, those associated with the World Heritage inscription of the site, did not allow local communities to use iron in the making of the house walls (an example of partial renewal of existing material with different material); they instead re-established, and trained the local communities in, the practice of thatching (a practice of partial replacement of existing material with same material), which they considered to be the 'traditional' practice of maintenance of the site (pers. comm. Webber Ndoro; pers. comm. Andrew Reid; Munjeri 2004b, 76-77; Kigongo 2005, 36-37). Therefore, the aforementioned cases tend to imply that practices of caring for sites have to be reduced in their own right or suppressed by heritage authorities in order to be recognised as relevant to official conservation systems, and still at a national heritage rather than a World Heritage level.

Given this failure of the World Heritage concept to take on board the majority of the practices of caring for living heritage sites, there are even cases that the declared recognition of a new World Heritage status may become a tool in the hands of national heritage authorities in their attempt to suppress or deny such practices. As it was noted with regard to the practice of repainting,

the phrase which seems to have acted like a bell on the Pavlonial dogs of the heritocracy is 'cultural heritage of all mankind' ... Defining something as belonging to that transcendant category is a means of excluding anyone who might have a particular interest in it. (Bowdler 1988, 521)

d) The continual process of evolving tangible and intangible heritage expressions / the evolving space of the sites.

The current theoretical framework and practice of heritage conservation is mostly based on sites whose process of spatial definition and arrangement has ceased. Generally speaking, evolution/ change of heritage expressions is unlikely to be accepted within conservation. Mehrotra notes:

Most conservation debates discuss change in terms of the loss of something, as opposed to new possibilities, mostly because people (especially the propagators and patrons of conservation effort) will easily react to any sort of new condition as worse than some "magic" moment in the past. $(2004,26)$

The failure of the current theoretical framework and practice of heritage conservation, in the context of a material-based and a values-based approach, to embrace living heritage sites is also demonstrated in the site of Meteora. The application of a material-based approach on the part of the Greek state (influenced by a Classicist approach towards the Byzantine past and attempting to embrace living Byzantine heritage in an already established system of heritage protection based on 'dead' Classical heritage, and not involving the religious and monastic communities in 
the conservation process) proved inefficient to embrace the strength of the Orthodox Tradition at Meteora as well as the power of the Meteora monastic communities. The result was a demonstration of extreme power by the monastic communities, as evident in the number and the scale of the unauthorised construction works. A values-based approach could not have been applied either: the monastic communities' connection with the site (who consider their monastery the centre of their life, their only home on earth, and the place of their God and their Abbot) could not have been regarded as a stakeholder group's value to be taken into account equally to the other stakeholder groups' values (eg. the tourists' or the local community's association with the site) under the control of the conservation professionals.

Therefore, given the failure of the current theoretical framework and practice of heritage conservation, also in the context of a values-based approach, to embrace continuity (all four criteria), a new conservation approach is required for the conservation and management of living heritage sites.

\section{Depending on the way continuity has evolved over time}

The way continuity (all four criteria) has evolved over time in the context of the changing broader conditions, and especially the enhancement of the continuity and the increase of the power of the communities, tends to lead to even greater complexities to the conservation and management of living heritage sites by the heritage authorities, with considerable implications for the original spatial arrangement and the fabric of the sites. Living heritage sites are unlikely to conform to the existing conservation principles and practices, particularly in the World Heritage context. With reference to the living Byzantine heritage sites cited above: At Mystras, on the one hand, where the continuity of the site has been suppressed and the power in site management has passed from the local community and the monastic community to the State / the Ministry of Culture, the State faces no significant problems in the conservation and management of the site, with an emphasis on the preservation of the fabric of those monuments that belong to the original (the Byzantine) phase of the site. At Meteora (and also at Mount Athos), on the other hand, where the religious tradition has been maintained and even enhanced over time and the monastic communities have retained their power in site management, there are considerable implications for the original condition of the space and fabric of the site, particularly in the strict World Heritage context, as illustrated in the number and the scale of the unauthorised construction activity. With reference to other living sites cited above: the Tanjore Temple, on the one hand, where the religious tradition has been suppressed over time and the power of site management has passed to the Government of India / the Archaeological Survey of India with reference to the modern scientific-based principles and with an emphasis on the preservation of the original space and fabric, has been designated at a national and an international (World Heritage) level. In the case of the Srirangam Temple and the Tirupati Temple, on the other hand, where the religious tradition has been maintained and even enhanced over time and the monastic communities have retained their power in site management, the changes in the space and fabric have not been embraced within the national and especially the World Heritage system: the Srirangam Temple is designated only at a state level, while the Tirupati Temple is a non-designated site. Similarly, in the case of the Temple of the Tooth Relic in the city of Kandy in Sri Lanka, where continuity has been maintained and even enhanced and the monastic fraternities have retained their power over time, the changes in the space and the fabric often move clearly beyond the existing principles and practices of conservation, particularly in the strict World Heritage context, as illustrated in the restoration of the site after the bomb attack.

Thus, it seems that the continuity of a living heritage site, including its traditional management mechanisms and maintenance practices, tends to be suppressed in order to be embraced by the strict World Heritage concept. 